\title{
Standardized Process Optimization and Realization of Zhejiang Tobacco Industrial Based on the Workflow Framework
}

\author{
Yingying Shen ${ }^{*}$, Fang Wu, Guang Yao and Zhenmin Miao \\ Information Center, China Tobacco Zhejiang Industrial Co., Ltd., Hangzhou 310000, China \\ *Corresponding author
}

\begin{abstract}
With the development of information technology, for the outspread need of management function of China Tobacco Zhejiang Industrial, to reinforce company standardization management is an important way to improve company market competitiveness, and realize cost decreasing and benefit increasing. Aim at the current management situation and practical demand of standardization, the China Tobacco Zhejiang Industrial do some research about the design and implementation technique of standard management workflow. In the paper, we present a framework based on component technology to support dynamic reconfiguration for the standardized Process workflow of Zhejiang Tobacco Industrial; whose workflow engine plays the role of a global coordinator to control different agents to fulfill the standardized process functions according to a predefined process model. And the Zhejiang Tobacco Industrial realized its' Standardized Process based on NPsuite. Work flow engine, which also optimized its' the process of standard audit, examination and approval, distribution.
\end{abstract}

Keywords—standardization management; information system; standard; workflow

\section{INTRODUCTION}

In the socialistic market economy system, enterprises in China's tobacco industry play a key role in the domestic economy, and its rapid development has contributed greatly to national finance. However, the enterprises are disturbed by their own unsustainable and weak competitive situation at present. So, independent innovation is a way to cure the problem. The Zhejiang tobacco enterprises always focus on the construction work of its' enterprise standardization, has released the measures for the management of enterprise standardization, developed a set of effective order, which can effectively organize the elements and links in the process of production and operation of the enterprise, so that the work to achieve standardization, scientific and procedural management, and design and implement a standardized management information system [1], which implement the work of standardization management and standardization system documents electronic management. But in the big data era of the rapid development of information network technology, the development of enterprises let enterprises face the pressure of lean management and structure raise requirements, and reducing the cost of increasing the efficiency, which have put forward higher requirements on the standardization of enterprise information management system. For those, the Zhejiang tobacco enterprises need to upgrade the original system, so as to meet the needs of the current information development and the extension of the company management function. Based on new development situation, face the existing problems, the tobacco industry need strengthen the construction of management information system, establish standardization system, and realize the standardization management of industry, in order to improve its' integrated management level, and comply with the requirements of the development of the times[2]

The standard system refers to a scientific organic whole formed by the internal relations of technical standards within a certain range, which is the basis for all large-scale lean production and an important part of constructing adaptive enterprise strategy [3]. And the standardized management plays a more and more important role in promoting innovation, improving competitiveness, promoting technological progress and promoting industrial development. Through the formulation and implementation of technical standards, management standards and working standards, we can ensure orderly integration of enterprise resources and promote the formation of a complete, coordinated and self-improvement management system and operation mechanism to get the best order and benefits of enterprises. Therefore, to construct the standardization management system of the tobacco industry is the inevitable choice for the development of the enterprise.

The paper presents a framework based on component technology to support dynamic reconfiguration for the standardized Process workflow of Zhejiang Tobacco Industrial; whose workflow engine plays the role of a global coordinator to control different agents to fulfill the standardized process functions according to a predefined process model. The remainder of this paper is organized as follows. Section II introduces related works. Section III puts forward the system framework. Section IV gives a case study of the Zhejiang Tobacco Industrial based on the system framework. Section V concludes the paper and presents future work.

\section{RELATED WORK}

To manage the evolution and the interactions of the business processes it is important to accurately model the steps to follow in the activity, the resources needed and the flow of information between the different parts involved (suppliers, manufacturers, clients, etc.). Workflows provide a way of describing the order of execution and the dependent relationships between the constituting activities of the business processes [4]. Workflows 
usually run concurrently, sharing a limited number of resources which are sometimes provided by third party companies.

The workflow representations have some highly diversified types. Some authors use other fields' representation models such as UML activity diagrams [5] or different types of petri nets (called Workflow-nets) [6, 7]. On the other hand other researchers have chosen to develop specific languages for workflow representation. A similar tool to UML for workflow modeling is Business Process Management Notation[8] (BPMN), it provides a graphical notation for specifying business processes in a Business Process Diagram. BPEL (Business Process Execution Language) originally was created to model web service interactions but it has also been used to model workflows, especially in service oriented architectures (SOA) [9], but also in scientific processes [10] or to model grid computing interactions [10]. Moreover, another interesting point of BPEL, is that can be easily transformed to other languages such as YAWL[11], BPMN (mentioned above) or to Petri net structures[12] as Hinz et al. and Brogi et al. show on their works. Van der Aalst et al. [13] propose a new workflow modeling language named YAWL (yet another workflow language). To create YAWL, the authors analyzed the different existing workflow modeling languages and studied which ones were able to represent the higher number of workflow patterns [14].

An alternative technique of modeling workflows is the use of workflow patterns (WP), which are also used to evaluate the performance of a workflow modeling language. The main research in this field has been done by Van der Aalst et al.; in [14] they present a classification and an analysis of the existing workflow patterns. In 2006 Russell et al. reviewed the list provided by Van der Aalst adding 20 more patterns which defined specific cases of the existing ones[14]. Albert Pla,et al. presents a new Petri net extension for modeling together workflow activities with their required resources: resourceaware Petri nets.[15], which include time and resources into the classical Petri net workflow representation, facilitating the task of modeling and monitoring workflows.

\section{SYSTEM FRAMEWORK}

\section{A. Standardized System Framework of the Zhejiang Tobacco Industrial}

The rapid development of Zhejiang tobacco enterprises, the increasing scale of the scale, the gradual growth of the management level, exposes the existing problems of the original standardized management system, such as low configurability of original system framework, lack of mobile and variable function lifting space, lack of system compatibility including restrictions on browsers and file formats, etc. what' more, the changes of the original system personnel are low in immediacy and integrity, which strengthen the interface with the company's human capital. In terms of system friendliness and ease of use, it cannot keep up with the development of current information and the need for the extension of corporate management functions.

In view of the above problems, at present, Zhejiang tobacco enterprise management content from the original standard and management system, extended to excellence benchmarking, target management, lean management and so on. On the basis of needs of the development of enterprise management and ensuring the continuity of historical data, we introduce the advanced, mature and extensible technical architecture to upgrade the original standardized information system, in order to upgrade the standard of management, and expand some related content as the system management, lean management, benchmarking excellence, target management, laws and regulations, commonly used functions, system management, etc. Based on the system function requirements, we present the Standardized system framework of the Zhejiang Tobacco Industrial shown in Figure I.

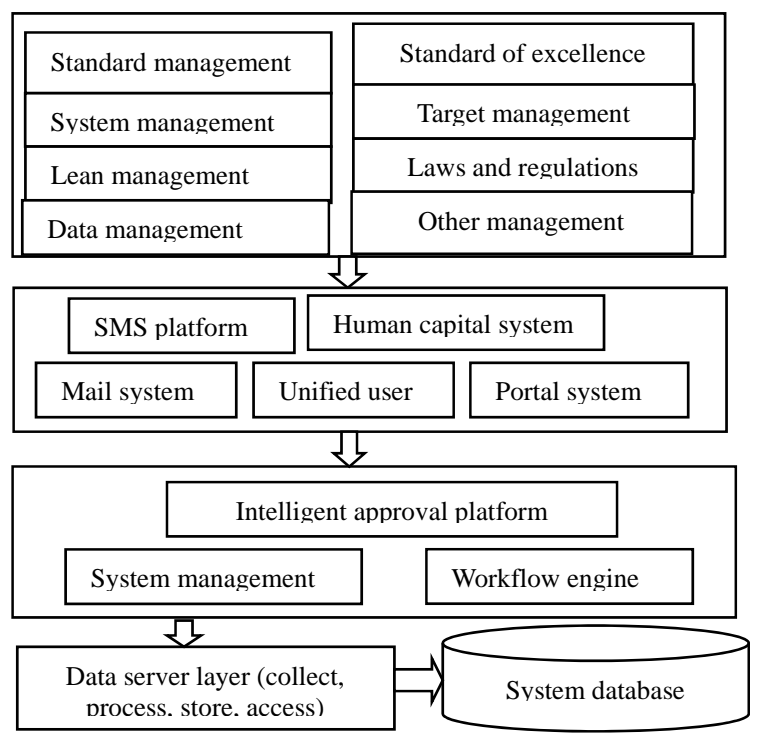

FIGURE I. STANDARDIZED SYSTEM ARCHITECTURE OF THE ZHEJIANG TOBACCO INDUSTRIAL

According to process logic, the system can be divided into following four layers: presentation layer, application layer, interface layer and data layer.

1) Presentation layer. It provides all the functions of standardized system of the Zhejiang Tobacco Industrial

2) Interface layer. It provides unified user interface and processes interaction between users and system in order to facilitate the completion of some human-computer interaction tasks.

3) Service layer. It provides the workflow management mechanism. As the core of standardized system, workflow engine is a runtime software service for workflow instance. This engine is responsible for online scheduling and resource allocation. It provides concurrent services for a number of external requests, responsible for the definition of standardization process, creates instance and manages its dataitem, calls external procedures and maintains workflow data.

4) Data layer. It provides unified data acquisition, processing, storage and access services. Data storage includes Workflow process definition data, organization role data, workflow data and user data, etc.

\section{B. Workflow Engine}

The WDK platform is a new generation of business architecture platform which is researched and developed 
independently by Hangzhou New Century Electronic Technology Co., Ltd. Which included an NPsuite workflow engine. The workflow engine is composed of four components and four interfaces: process definition tool, workflow execution service, workflow client application, workflow management tool and so on. The structure is shown in Figure II.

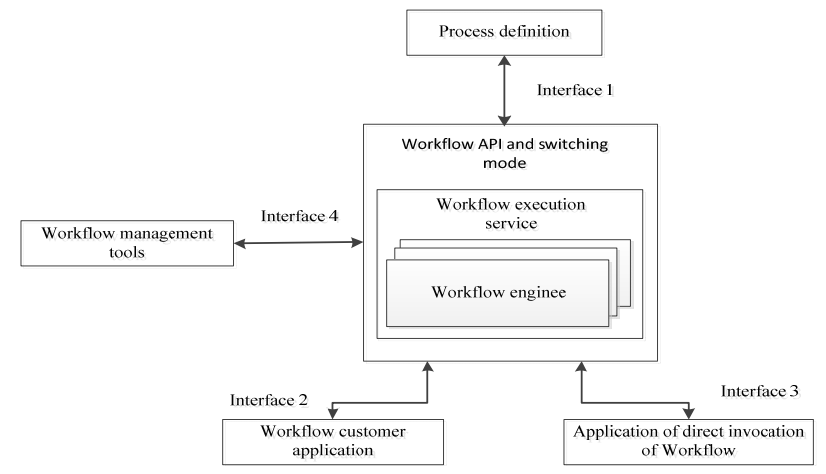

FIGURE II. THE STRUCTURE OF NPSUITE WORKFLOW ENGINE

1) Process definition tools. It describes a process, defines the steps of the business flow and the flow rules, and defines who is done by each business step.

2) Workflow execution service. It consists of workflow engine, provides a process instance execution environment, mainly to complete the instantiation of the process and the execution model, the process and activities for navigation, and business system interaction activities, maintenance workflow control data and workflow relevant data and other functions.

3) Workflow client application. It is done by the workflow task table manager and the user operation. The function of the task or activity assigned by the user to operate the workflow management system. The workflow task table manager is a software module that manages the interaction between the user and the worksheet.

4) System management and monitoring tools. It monitors the flow of workflow in the whole organization, and provides a series of management functions to achieve security, process control and authorized operation.

5) Interface 1 (process definition, input and output interface). It is the interface between workflow definition tool and workflow execution service, whose main function is to load process definition files.

6) Interface 2(client function interface). It is the interface between the workflow execution service and the workflow customer application, which has the most important interface specification. It appoints the way of functional operation between client application and workflow execution service includes functions of process instance management, task item processing, process monitoring and so on.

7) Interface 3(activate the application interface). It is the interface between the workflow engine and the directly invoked application, and the business system calls the interface in the process engine to complete the flow of the business.

8) Interface 4(system management and monitoring interface).
It is the interface between workflow execution services and workflow management tools, including role management, user management, monitoring tools and other functions.

\section{CASE STUDY}

Standard management is the most important function of standardization management system in Zhejiang tobacco enterprises. It implements the whole process of automatic management of standard revision, application, audit and issuance to standard electronic filing. The specific process flow is shown in Figure III.

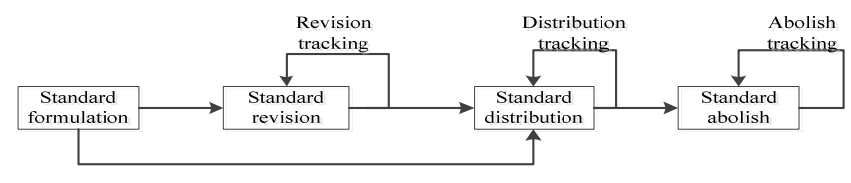

FIGURE III. STANDARD MANAGEMENT WORKFLOW

In the standardization information management system of Zhejiang tobacco enterprise, the design of the work standard management process is divided into four parts: making, revising, distributing and abolishing, and each link has the function of tracking and monitoring. The system divides the standard examination and approval process into two processes: the work standard of the department and the work standard of the two factories, which facilitates the simplification of the audit process and the revision of the working standards of the subsequent versions. The revise process of the work standard of this department is shown in Figure IV. And the revise process of the work standard of the two factories is shown in Figure V.

As shown in two figures above, there is a difference between the review and approval process of the work standards of the Department and the two factories in the Zhejiang tobacco enterprises. The work standard of this department is reviewed by the leader and the standardization administrator of the return department. Then it is audited by the director and the standard technical committee. Finally, after the approval of the leaders, it is issued to the departments and sections through the general control and control, and then issued to the relevant personnel. While the work standard of the two factories is reviewed by the leadership and the standardization administrator of the Department. Then the director and the standard technical committee, as well as the department standard administrator audit, after the final examination and approval by the leadership, it is issued to the relevant personnel through the departments to the sections. In the process of standard distribution, the system has realized the function of the group distribution and the fuzzy query function of the personnel, which can solve the problem of too many personnel and difficult choice. At the same time, the system has also realized the standard replication function, the standard that need to be issued or reissued for the same personnel, and can be duplicated by standard to achieve one key replication. 


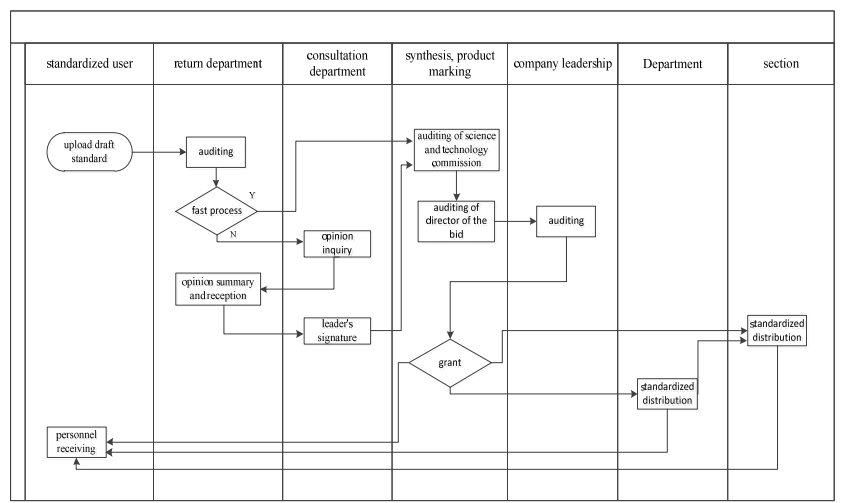

FIGURE IV. REVIEW AND APPROVAL PROCESS OF THE WORK STANDARD OF THE DEPARTMENT

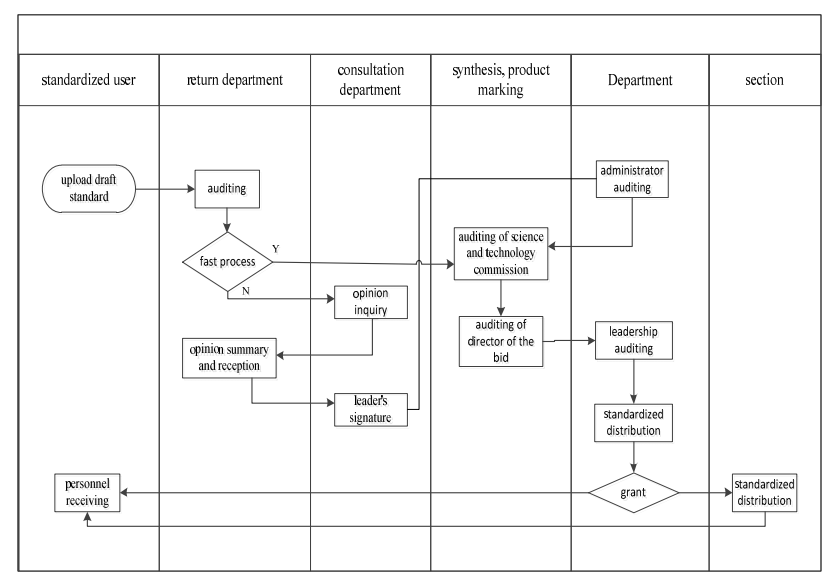

FIGURE V. REVIEW AND APPROVAL PROCESS OF WORK STANDARD OF TWO FACTORY

\section{CONCLUSIONS}

Aiming at the existing problems of the original standardization management information system, Zhejiang tobacco enterprises upgraded the technology architecture of the original system to form a new standard management information technology platform, including workflow engine, mobile platform, and development framework and so on. The new technical architecture conforms to the SOA architecture specification, with good scalability, cross platform capabilities, and higher compatibility. Based on a unified technical platform, WDK, the Zhejiang tobacco enterprises redevelop and reconfigure all the processes, forms, users and rights of the original standardized management system. And the original function is optimized and a series of practical functions are added to enhance the adaptability and ease of use of the system. The improved system can improve the utilization rate of the enterprise data information and improve the management efficiency of the enterprise. With the application of the system, it can further promote the innovation and application of information technology in the enterprise, and create greater economic and management benefits for the enterprises. The standardized management information system of Zhejiang tobacco enterprise has expanded the functions of system management; target management, lean management, benchmarking management, laws and regulations based on the intelligent management and control of standard management, and realized the integration of enterprise management. It has a good prospect in the application of tobacco manufacturing enterprises in China.

\section{ACKNOWLEDGMENTS}

This paper is supported by the fund project of Zhejiang Tobacco Industry Co., Ltd. Standardized information management system (120150059).

\section{REFERENCES}

[1] S.Yingying, W.fang, Y.Guang, Application on information management system of standardization for cigarette manu facturing enterprises, Bulletin of science and technology, vol.32,no.7, 2016,pp:149-153.

[2] Z.Juan, Y.Ying, S.Juan, Study on sensory contribution of tobacco making process, China science and technology information,vol.19,2014,pp:170171

[3] Z.Chune,A brief discussion on how to do standardized management of tobacco enterprises,Enterprise transformation and management, vol.8X,2014,pp: 174-174.

[4] J.Tick,Workflow model representation concepts, Nemzetkzi Szimpziuma 7th International Symposium of Hungarian Researchers on Computational Intelligence,2002,pp:329-337.

[5] [5] A.Kalnins,V.Vitolins, Use of uml and model transformations for workflow process definitions,Computer Science,2006.

[6] S.Rinderle, M.Reichert,P.Dadam,Correctness criteria for dynamic changes in workflow systems: a survey,Data \& Knowledge Engineering,vol.50,no.1,2004,pp:9-34.

[7] W.M.P.van der Aalst, B.F.van Dongen, J.Herbst, L.Maruster, G.Schimm, A.J.M.M.Weijters,Workflow mining: a survey of issues and approaches,Data \& Knowledge Engineering, vol.47,no.2,2004,pp:237267.

[8] M.Muehlen, J.Recker,How much language is enough? theoretical and practical use of the business process modeling notation,International Conference on Advanced Information Systems Engineering vol.5074,2008,pp: 465-479.

[9] K.Pant,Business Process Driven SOA using BPMN and BPEL: From Business Process Modeling to Orchestration and Service Oriented Architecture, Packt Publishing ,2008.

[10] B.Wassermann, W.Emmerich, B.Butchart, N.Cameron, L.Chen, J.Patel, Sedna: A bpel-based environment for visual scientific workflow modelling. In Workflows for eScience - Scientific Workflows for Grids. Springer Verlag ,2007.

[11] Brogi, R.Popescu, A.Brogi, R.Popescu,Bpel2yawl: Translating bpel processes into yawl workflows,Faseb Journal,2006.

[12] S.Hinz, K.Schmidt, C.Stahl,Transforming bpel to petri nets,Lecture Notes in Computer Science,vol.3649,2005,pp:220-235.

[13] W.M.P.van der Aalst,Ter, Yawl:yet another workflow language. Information Systems,vol.30,no.4,2005,pp: 245-275.

[14] N.Russell,Arthur,W.M.P.van der Aalst, N.Mulyar,Workflow controlflow patterns: A revised view,Tech. rep., BPMcenter.org,2006.

[15] A. Pla, P.Gay, J. Meléndez,B. LópezPetri,net-based process monitoring: a workflow management system for process modelling and monitoring, Journal of Intelligent Manufacturing,vol.25,no.3,2014,pp:539-554. 